\title{
The Status of Daily Physical Activity in Northern Ontario's Elementary Public Schools
}

\author{
Greg Rickwood \\ Correspondence: Greg Rickwood, Nipissing University, 50 Wellington Street, Brantford, Ontario, N3T2L6, \\ 519-752-1524 Ext. 7554, Canada
}

Received: December 11, 2014

Accepted: December 31, 2014 Online Published: February 13, 2015

doi:10.11114/jets.v3i2.605

URL: http://dx.doi.org/10.11114/jets.v3i2.605

\begin{abstract}
The importance of daily physical activity (DPA) for children and youth is highlighted in Canada's Active Healthy Kids annual report on fitness. Since 2005, this report has revealed that elementary-aged students are spending most of their waking hours stationary, in front of screens (phones, televisions, computers). To counteract this trend, the Ministry of Education in Ontario introduced policy that ensured elementary schools deliver 20 minutes of DPA beyond Physical Education classes. However, 9 years later, students remain relatively inactive during school hours. This study examined the barriers believed by Northern Ontario elementary teachers and administrators to influence their abilities to include DPA into their daily timetables. Results showed that the depleting priority of DPA in elementary schools, the absence of student and teacher mentorship, and fewer leisure time minutes during the school day were key variables in the exclusion of school-based DPA. Interestingly, many of these challenges were overcome in schools governed by school-based practices and policies that supported DPA. In these particular schools, participants expressed that their internal resources were the best defense against detractive forces that marginalized school-based physical activity.
\end{abstract}

Keywords: school culture, daily physical activity, teachers, administrators, beliefs

\section{Introduction}

Recent Canadian data suggests that a mere 9\%of school-aged boys and $4 \%$ of girls accumulate the recommended minimum of 60 minutes of moderate intensity, daily physical activity (DPA), and spend over 8 hours per day in sedentary pursuits(Active Healthy Kids Canada, 2013; Colley, 2011). Additionally, statistics from the Canadian Health Measures Survey determined that $31 \%$ of boys and $26 \%$ of girls (15-19 years) are either obese or overweight (Tremblay et al., 2010). Of particular concern are the low rates of physical activity (PA) among youth living in northern and rural communities compared to their urban counter parts (Comte, 2013). Low levels of PA among youth are associated with negative effects on psychological well-being (Kantomaa, Tammelin, Ebeling, \& Tannila, 2008), the increased risk of developing chronic diseases in adolescence(Ruiz \& Ortega, 2009)and the potential of low levels of PA persisting into adulthood (Malina, 2001; Telama et al., 2005); thus, perpetuating health risks as individuals age. Therefore, mentoring active lifestyles to younger generations may help establish life-long patterns of PA and reduce health deficiencies later in life (Adami, Day, Trichopoulos, \& Willett, 2001; Horton, 2009; Janssen \& LeBlanc, 2010; Janssen, 2008).

Schools are places where active lifestyles can best be promoted to children and youth due to their time spent at school, the presence of physically-active adult role models and physical activity opportunities (Belanger et al., 2009; Leatherdale \& Rynard, 2013). To promote the significance of DPA for children and youth, Ontario's Ministry of Education mandated that all elementary students (Kindergarten to grade 8) receive 20 minutes of DPA (Ministry of Education Curriculum, 2005). However, the inclusion of DPA can be trying for some schools because of budgetary constraints, teacher/administrator turnover, yearly school success plans that focus on reading and writing and reduce the time dedicated to PA and PE (Datar \& Sturm, 2004), and limitations with recreational spaces on school grounds (Koplan, Liverman, \& Kraak, 2005; Rosenfeld, 2004; Trudeau \& Shephard, 2005). Deflecting the focus away from DPA negatively influences the number of minutes students are active at school (Koplan et al., 2005; Trudeau \& Shephard, 2005).

\subsection{Rationale}

The majority of studies investigating the relationship between school settings and student PA levels have largely focused on the influence of the built environment in elementary school settings (Kindergarten to grade 8) (Cohen, Scott, 
Zhen Wang, McKenzie, \& Porter, 2008; Haug, Torsheim, \& Samdal, 2008; Lanningham-Foster et al., 2008; Williden et al., 2006). More recently, there has been a call for studies that reach beyond a school's physical environment to understand how the 'whole school' impacts student PA levels (Leatherdale, Manske, Faulkner, Arbour, \& Bredin, 2010; Leatherdale \& Rynard, 2013; Rickwood \&Singleton, 2012). Research is important in this area because student PA levels are associated with the less tangible components of a school's culture (i.e. teacher and principal values, attitudes, and behaviours associated with physical activity) (Barnett, O'Loughlin, Gauvin, Paradis, \& Hanley, 2006; Bauer, Patel, Prokop, \& Austin, 2006; MacQuarrie, Murnaghan, \& MacLellan, 2008). Moreover, other researchers have verified that school-wide acceptance of the importance of daily physical activity significantly influences school-based PA opportunities and student PA levels (Barnett et al., 2009b; Haug et al., 2008; Loucaides, Jago, \& Charalambous, 2009; Mahar et al., 2006; Naylor, Macdonald, Zebedee, Reed, \& McKay, 2006; Rickwood \& Singleton, 2012). Therefore, using an in-depth, cultural approach to investigate the influence the 'whole school' has on school-based PA opportunities and student DPA levels is warranted.

\subsection{Theoretical Framework}

Edgar Schein's (1985) cultural systems theory-a theory grounded in earlier group behaviour, social systems, and organizational functional analysis theories (Homans, 1950; Merton, 1968; Parsons, 1951) proposes that as an organization evolves and becomes more resilient, its culture is embedded into its members' sub-conscious. Schein refined his theory to embrace the knowledge that behaviours within an organization could only be interpreted in the specific context in which the cultural system existed (Schein, 1999). He believed that an organization's cultural system contained three distinct levels: (i) school artifacts (i.e. physical layout, how people dress, smells in the hallways, trophy cases) (Schein, 1990); (ii) school policies and practices, and (iii) member beliefs concerning school values. For this research, Schein's deepest levels of culture (school practices/policies; member beliefs) will serve as theoretical constructs.

\subsection{Research Questions}

The following two questions will guide the exploration of the influences school's practices, policies and member beliefs have on student DPA levels and school-based PA opportunities:

1. What are the perceived barriers that influence elementary school teachers' and/or administrators' participation in mandated DPA and other school-based, PA opportunities?

2. What is the relationship between elementary school teachers' and administrators' beliefs around mandated DPA, other school-based PA and student DPA levels?

\section{Method}

The descriptive case study methodology was appropriatefor itsattentionto how and why things happen, and ability to interpret cultural realities and differences between intentions and actual behavioural outcomes (Anderson, 1993). Moreover, case studies are useful in understanding the breadth and width of particular relationships within organizations (i.e. schools) (Noor, 2008; Patton, 1987).

\subsection{Data Collection}

The focus interview method was selected because of its flexibility to manage each participant differently while asking the same questions (Noor, 2008). The interview items (Table 1) were drawn from the Modified Active PASS (Physically Active School Settings) survey (MAPS). This modified survey is a valid and reliable tool for examining factors associated with school culture that influence school-based physical activity opportunities and student physical activity levels (Rickwood, Temple \& Meldrum., 2011a).

Table 1. Focus Interview Questions

\footnotetext{
1. This school's values concerning physical activity are explicit (i.e. policy documents, assembly announcements, school newsletters).

2. At this school, students have opportunities to learn how to organize games, sports, and other physical activity programs at school.

3. At this school, staff are encouraged to be physically active role models (i.e. walk/run with students during Terry Fox walks/runs).

4. This school provides opportunities for staff and students to be physically active together (i.e. intramurals, Terry Fox walks/runs, class activities).

5. This school provides organized physical activity opportunities for students before, during, and after school hours (i.e. running clubs, swim teams, environmental clubs).

6. At this school, staff members promote and facilitate student participation in physical activities during leisure times (i.e. organize intramural activity programs, supervise open gym sessions, etc.).

7. This school recognizes students through celebrations, certificates, and/or rewards for physical activity participation.

8. This school discourages the removal of time dedicated to PE or leisure time as punishment.

9. At this school, staff is encouraged to share their personal physical activity interests with students (i.e. running a marathon, yoga instructor).
} 
Initially, participants were given the following response options: strongly disagree, disagree, undecided, agree, and strongly agree, and then asked, (i) "Why do you feel this way?" (ii) "What experiences have solidified your beliefs on this issue?" and (iii) Have your beliefs changed over your time spent in this school? If so, what circumstances or experiences have altered your beliefs?" Furthermore, if someone strongly disagreed with a statement, he/she was asked to think of school policies or practices that might alter their beliefs. In turn, if a teacher/administrator strongly agreed with a statement, they were asked to give reasons why they believed the school was achieving success in this area.

Verbal responses were recorded using Quick Time (Macintosh application) that allowed for event sequencing and replays of direct quotes (Hammersley \& Atkinson, 1983; Warren \& Karner, 2010). One month post-interview, participants were provided with word-processed transcripts of their comments and asked to review them for clarity and representativeness.

\subsection{Data Organization}

Participant comments were inputted into the latest version of word-processing program Microsoft Word in search of thematic patterns; the preferred method of data organization in qualitative research (Warren \& Karner, 2010). Miles and Huberman (1984) confirm that analyzing qualitative data is more efficient when categorized into themes, flow charts and/or calculating the frequency of similar statements.

The next step involved clustering participant responses according to school practices, policies and member beliefs (Schein, 1985). Yin (1994) contends that clustering is the most pragmatic method for dissecting data according to its theoretical framework. To accomplish this, each level was afforded a singular colour (i.e. school practices/policies = green; member beliefs $=$ red) for consistent transfer of the data into the cultural systems' framework.

\subsection{Participants}

Study participants were purposively sampled from English-speaking, public elementary schools $(\mathrm{n}=10)$ in a small, Northern Ontario school district. Teachers and administrators from each school were invited to participate; five teachers (females=4; males=1) and four administrators ( 3 females; 1 male) from four schools consented. All schools were urban-based, and located within a 7-10 kilometer radius of one another. Teachers and administrators were of interest in this study because of their influence on school-based PA practices and policies, and 'insider' perspective into their school's PA culture (Schein, 1999). To protect the anonymity of each person and school, pseudonyms replaced actual names:

Tessa: currently a grade one teacher but was the school's Learning Resource teacher for eight years. She coaches the school's soccer, volleyball, baseball and track and field teams.

Tina: has taught for 12 years between two elementary schools where she held (and holds) the position of Learning Resource teacher. She teaches self-contained, special needs' classes (boys only-grades JK to 6). Currently, Tina helps coach her school's baseball, soccer and track and field teams.

Gabrielle: the principal at her school for the last four years. It is her 26th year in education with 16 of those years being in administration. She has also been a vice-principal at other elementary schools in the district and taught grade three for 10 years specializing in Language Arts.

Heather: the acting principal at her school - she has 17 years experience teaching primary and junior grades along with being a learning resource teacher. She has spent her entire career at this school. Heather is also the school district's elementary sport coordinator.

Katie: has taught grades one to four over her career (29 years). For the last 15 years, she has been the grade three teachers at this school. She has coached the school's cross-country, track and field, volleyball and basketball teams.

Maddy: is the learning resource teacher at her school - she has held this position for the last eight years. Before she took on this role at her current school, she taught grades two and three at a special education focused school in the United States for 15 years. Maddy has always been her school's cross country and track and field coach.

Jessica: the principal of her elementary school for the last two years and worked in the school district for 11 years. She has coached girls' and boys' ice hockey, track and field and volleyball over her teaching career.

Jamie: has been at his school for three years. He teaches English, Health and PE and junior Science to half of the school's students $(\mathrm{n}=220)$. Jamie coaches cross-country, track and field, boys' volleyball and is the school's primary lead for the Terry Fox run.

Ray: the school's principal for the last two years, and an educator with this school district for 27 years 7- 11 of these years as an administrator. Ray has taught grade five at various elementary schools in the district; he coached cross-country, volleyball and track and field during his teaching years. 


\subsection{Procedures}

The University and the local school district's research ethics review boards, along with the principals of the participating elementary schools, granted study approval. Immediately thereafter, teachers and administrators were invited to participate through a written letter of invitation placed in their school mailboxes, and on study advertisements within the principal's weekly blog to staff. Interested participants provided informed consent and were individually briefed on study goals, benefits and expectations. Interviews occurred during school hours within a secure location on school grounds; data collection was finalized in April 2014.

\section{Results}

Participants' statements were synthesized and analyzed according to Schein's (1985) levels of organizational culture for a more complex analysis of the factors believed to be associated with school-based PA opportunities and student PA levels in the studied elementary schools. Using this framework, three sub-themes were identified within the school policies and practices' level of culture, and three sub-themes were distinguished at the member beliefs' cultural level. These themes are discussed in the following paragraphs.

\subsection{School Policies and Practices}

The school-based practices and/or policies believed by most participants to be major barriers to school-based PA were the diminishing priority of DPA, the methods by which PA and PE were being used by elementary teachers, and the impact of administrative turnover.

\subsection{Mandated DPA}

Every Ontario elementary teacher is expected to deliver 20 minutes of DPA to his/her students. To an outsider, this may appear to be a reasonable request for teachers to carry out, but as indicated in the data, incorporating these 20 minutes, particularly on a non-PE class day, can be troublesome. For example, Jamie learned that:

It is all about time to organize DPA and meet with other teachers about what they are doing in DPA with their classes. In the past, we used to have DPA for the whole school-everyone would come out of their class and music would play in the halls-not anymore.

Katie found similar challenges at her school to include DPA. She said:

DPA is supposed to be 20 minutes a day but it is very hard to fit that in with the curriculum we are covering. So, a lot of times when you are doing it on your own, it's very easy to say oh well, I have to finish my Math lesson.

Moreover, Wendy's beliefs on DPA at her school were:

DPA was the big push a few years ago. I know one school in the district did it every morning as a whole school. What happens is you have prep time, scheduling and other things to consider. It is the kind of thing (DPA) that falls off after a while

At another elementary school, Tina believed that DPA was a priority a few years ago but it has fallen into the "fit it in when you can" category.

Even with DPA, it isn't enough physical activity for these kids. We had the opportunity to go see a workshop and they talked about how doing different activities can help the different parts of the brain. We brought it back to the school and used it that year and haven't used it since.

Maddy stressed the same concerns with DPA as her colleagues - she felt that:

DPA is 20 minutes a day and it does cut in. It needs prep time and it does cut into the curriculum which is focused on reading and math - where does Physical Education fit in?

\subsection{Physical Activity: A Behaviour Management Strategy}

Elementary teachers and administrators in this study noticed that some of their colleagues practiced the use of PA (or removal of $\mathrm{PE} / \mathrm{PA}$ ) as a deterrent for inappropriate classroom behaviour. In their opinion, teachers have learned that PE and leisure time activities are "rewards" they can use to manage student behaviour. Begrudgingly, Katie has seen this happen in her school:

A lot of times for punishment, the kids have their nutrition breaks taken away and they (students) are told they have to stand by the wall. When I am on duty outside, I have my kids run to the fence and back so many times as their punishment.

Maddy has found this same strategy instituted at her school:

If the students are misbehaving, they have to stand against the wall but now, they do laps which can be seen as a 
punishment. Another practice I see is a teacher teaching PE and then having a student doing seatwork during PE class. I don't buy that.

At his school, Ray believed the removal of PE or PA was used as an incentive for desired student behaviour. He said:

The taking away of PE time should be age appropriate and whether it is just a three or five-minute time maximum, then the students should be allowed to rejoin the class. I think for some staff members, if they have used all the tools in their toolbox, then they might resort to this tactic.

Tina was against this strategy for behaviour management but recognized that her teaching partners used PA/PE as a behavioural carrot. In her words:

One of our teachers makes their students run during nutrition break if they were misbehaving in their class. They (students) were still doing PA, but no one likes running, especially as a punishment for a few kids' behaviours.

\subsection{Administrative Turnover}

Support from the top (administration) was outlined as a positive influence on teacher involvement in school-based PA opportunities and indirectly, student DPA levels. Katie mentioned:

You have to have an administrator on board that provides time for teachers to coach. A lot of times, teachers will coach and then be told they can't get a supply teacher to cover for them when they take their team to an event. So, if you have an administrator who can find money for the supply, teachers can coach and know they are supported.

Maddy agreed with Katie's interpretation around administrators' influence:

Getting a new principal every other year is challenging especially because we are an established staff. I lead an outdoor activity program and we did have it up and running at the school for a while. It depends on what the push is and who the administration is and it changes.

Being in her role as sport convener for the district, Heather understood the importance of administrators who promoted school-based PA. For example, her experience had been:

Often, there is no release money for teacher-coaches and that's something the principal has to deal with. Depending on your administration, they may give up some school funds to release you to attend team functions.

Ray had talked with his teachers about the obstacles they faced when trying to book time off to attend their sport's team's game or a professional development workshop during school hours. Ray strongly supported his teacher-coaches but mentioned that there were other barriers:

There are some teachers that apply for funding to attend coaching clinics or take their teams to tournaments-waiting for it to be processed-it's just too much. So, some teachers just say forget it and then they (and their teams) lose out on these professional and player development opportunities.

\subsection{Member Beliefs}

Distinct from school policies and practices, participants believed there were additional intangible variables that influenced school-based PA opportunities and student DPA levels. These factors included the absence of formal mentorship (teachers and students), cultural changes in education, and current parent/guardian/student values around PA. In the following paragraphs, these themes are expanded upon.

\subsection{Mentorship}

According to participants, one influence on school-based PA and student PA levels was the declining number of teacher-coaches that were willing and prepared to lead sport and/or PA-based programs. Tessa recalled:

When I started 13 years ago, it (coaching) was part of your job. Like this year, there wasn't going to be a volleyball team and I wasn't going to let that happen so I coached the team. I don't know anything about volleyball but I decided to coach.

This issue was not concentrated to one school in the district. At her school, Heather stated that lack of qualified teacher-coaches was a problem:

The new teachers at our school seem to be gung ho with coaching at the start of the school year but as their teaching responsibilities take over, coaching takes a back seat.

Furthermore, experienced teachers in this study believed that new teachers were not taking the initiative to learn about sport/PA programs, or investing the necessary time to learn about, and participate in physically active, extra-curricular opportunities. Jamie proclaimed: 
When I started teaching, I was it. I was a grades 7-8 teacher so I did everything. I find it sad that they (new teachers) are not coaching-that's fine but this forces administration to bring in community people/coaches.

At her school, Maddy has also witnessed the lack of interest from new staff in extra-curricular participation:

We all have our own personal interests in it (sport or fitness) but no one seems to want to take sport's teams over. I have always been the cross-country and track and field coach at this school. We have volunteers that will help with these teams when I leave in a couple years. I don't know what will happen with it.

Ray concurred at his school, new teachers were not entering the profession with the idea that they should be helping out with activities outside of academic school hours. For example, he found that:

More recent graduates, I find have the mindset that they are here from 9-3:30 pm then they are done. They are less likely to get involved. The more experienced teachers are looking to move on and pass on the torch of their coaching to the new teachers and they aren't there.

Some of the participants indicated the absence of a PE specialist on staff as a contributor to declining DPA levels of students, diminished importance of daily PE and in general, a reduction in school-wide PA opportunities. For example, Heather explained:

I think the Ministry of Education has presented it (PA) as not important because students only require one PE credit in high school to graduate. This also means you have less PE teachers. This means that there are less qualified teachers to coach varsity teams.

She continued her thoughts by recalling her days as an elementary student:

In my time, there were PE consultants. If we had them today, I think these issues would not exist. As the district's sport convener, I try to replace the PE consultant's role but because I oversee all elementary schools and teach here, I simply cannot be present in every school when they need me to be there.

Maddy supported Heather's beliefs because of her experience teaching in a school with PE specialists:

I worked at a school in the U.S. that had their own PE teachers. We had teachers trained in teaching Physical Education. I think there were four PE teachers at the school - the classroom teacher would participate in some activities based on their comfort level.

Ray also valued PE specialists:

Now, we have French starting in JK/SK which involves French teachers teaching every subject. So, when they need prep time, I cannot put a teacher in that classroom that cannot speak and/or write French. I believe it is the same with PE-there are many benefits to having PE specialists on staff. If you want kids to be active, get PE specialists in the schools.

\subsection{Cultural Change}

Experienced teachers and administrators are stepping away from participation in school-based PA opportunities because of the increased responsibilities of the job and for personal reasons. Jessica wanted to be more involved in coaching but said, "I have a young family right now and I'm sure that if I wasn't in that role, I would be actively involved in sport at the school. My home responsibilities are my number one barrier personally." Furthermore, Katie stated that, "I do less coaching as I get older as I have my own kids involved in sports which gets pretty busy."

On the other hand, daily teaching and administrative responsibilities have become so burdensome for some educators that coaching and/or involvement in extra-curricular, PA opportunities have become secondary. For example, Tessa stated:

Time is always a difficult thing. I can't just stop at three and do whatever so you need more than one person coaching in case I can't be there or if something comes up. I had more time to coach when I was a resource teacher. There was more paperwork and such to do during the day and at lunch so you could time manage more because you don't have kids with you all day.

Ray was also frustrated that he could not contribute more to physically active, extra-curricular activities. He said:

I find it very challenging now to help out as I did when I was a classroom teacher. As a teacher, I had more of a head-coaching role but once I entered administration, I never know what my day will bring and cannot guarantee that I can make all the practices and games.

As principal of her school, Jessica faced similar challenges:

In my role here, what prevents me from doing something physically active with students at lunch would be because I am dealing with other issues. Whether it is staff bringing me issues or students at nutrition breaks - I don't get a break. 
Another factor that limited school-based PA opportunities and ultimately, student PA levels was the increasing concerns around teacher liability. Teacher-coaches and other school sport/PA leaders were prioritizing their job security over taking risks with participation in extra-curricular activities. Jessica found that her staff were starting to bring this topic up more:

People are scared-they don't want to take on things because of the liability. Teachers are apprehensive about being held liable - even the issue about driving kids to sporting events. Fewer teachers are taking these risks for students.

Heather found legal liability to be at the forefront of teacher's minds at her school as well. For example, she felt that:

Maybe 15 years ago, a teacher could be pretty hard on the kids. I find even as a teacher-coach, parents come to me and tell me that I am working them too hard. The other issue is that we are no longer allowed to drive kids to practices or games.

Gabrielle also confirmed the attention teachers needed to dedicate to student safety:

Some teachers want to be physically active with the kids. However, they need to be careful with that as there are health and safety aspects - you must be supervising the kids at all times. If you are playing with the kids, you also need to be watching all the kids too-the teacher may miss what is going on in the corner.

Another factor that influenced elementary, school-based PA was declining student enrolment. Fewer students meant less full-time teachers and potentially, reduced school-based PA opportunities outside of PE classes. Ray talked about this reality and how it impacted PA opportunities at his school:

We don't have a lot of full-time jobs coming through. So, we are getting teachers who are working at a $40 \%$ or $60 \%$ teaching workload at our school, and then they teach at another school for the rest of their workload. With this, there is the question of how much commitment they will dedicate to our school.

Jamie reaffirmed Ray's observations-he noticed at his school, sport teams were folding because "the new teachers were not replacing the old." He explained:

Declining student enrolment is taking its toll. The new teachers are quitting because they are not getting full-time jobs. The more experienced teacher-coaches are getting tired of coaching and there is no one there to take over.

Heather also voiced her beliefs about the influence declining enrolment was having on school-based PA:

We only have 160 children at this school. This means fewer staff bodies and less activities for the students. The problem is if you don't have the group of new teachers coming in that want to do it (coach), sport programs do not continue.

\subsection{Parent/Guardian and Student Values}

Elementary teachers and administrators in this study discussed the profound influence parents/guardians had on their child's desire to be active at school. Tina believed this to be true as outlined in the following statement:

Most of our kids are coming with no energy-it is educating the parents too. Most of the kids' lunches are full of unhealthy food too. I think it is our (teachers) inability to think outside the box-we have to if we are going to get these kids active.

She also said:

Society has changed so much-kids used to come home from school and go out to play but now, both parents are working so they go and sit in day care. When it is time to go home, the parents, after a long day at work, do not want to spend time doing physical activity with their kids.

Gabrielle talked about the challenges with parents/guardians at her school:

The parents at this school are not committed to picking their kids up after school. If the parents do not support before or after-school activities, it is impossible to get our kids interested in participating in these activities.

Heather was adamant that parents/guardians were the key to getting kids active at school. She felt:

There is a mindset that stems from home. Parents are not really concerned with helping you (the teacher) come up with strategies to get their kid motivated to be active but it is true. You (the teacher) shouldn't have to force a child to do anything-they should want to be physically active.

Moreover, Heather saw this influence trickle into school-based, competitive sport teams as well:

We are begging students to attend sports' team tryouts but there is no work ethic. I think this comes from the parents too. We are getting notes from parents saying their kids can't come to practice. As a parent myself, I would never say my son was not going to a team practice that he was chosen for.

Parents/guardians were also perceived to influence their child's participation levels in PE. For example, Heather's 
experience had been that:

Parents are too quick to excuse kids. Kids in any subject don't want to work but especially in PE. If the child has to run the mile, you'll see a note. On our mini track meet days, you'll get multiple notes from parents saying that their child doesn't have to run.

She went on to explain:

Energy breeds energy-if the kid is in shape, I don't know someone who doesn't want to go outside and run. But, if the kid is lethargic, they do not want to run and then come the letters from parents. The kids that need to be active are the ones bringing the notes. It's the enabling parents.

Educators at other schools in the district were noticing the same pattern. For example, Ray felt:

It is a challenge when some students do not want to go on the cross-country ski trip because their parents do not approve of it. Even those students who are a little heavier than the other students can benefit from participating in these physical activities.

According to study respondents, student values regarding PA were misguided, and had changed significantly from when most of the teachers and administrators in this study started in education. Tina said that, "They (students) are lethargic, they don't give respect that they need to, and the primary kids lack motor skills. Today, kids are inside playing video games-when we were kids, we were outside all the time." To further support her position on this issue, Tina revealed that:

Kids don't want to be active anymore. They are coming in with the values that it (PA) is not important. Maybe we (educators) are not presenting the importance of physical activity correctly.

At a separate elementary school, Gabrielle witnessed the lack of commitment from students to be active. She commented:

It's not that the teachers are not willing to put in the time to organize and lead physical activities during nutrition breaks and after school, but student interest is so low that it is not worth their time.

Katie, an experienced primary teacher, offered specific examples at her school of students' sedentary desires:

At our school, we want the kids to run a marathon by the end of the year so every day, for 20 minutes, we run and then in June, we have this big celebration and all the schools that attend, they do the last two kilometers together around a track. But, our kids aren't really into it-we really have to push them to run for the 20 minutes.

Katie followed up with her belief that:

In general, kids at this school are so into their video games and that's all they do and that's their life. That's what they like to do and they don't like physical activity. Even during DPA, we (teachers) are constantly having to tell them to get going, get moving-it's a struggle to get them going.

She had direct evidence to support her beliefs because of the feedback she received from her students about how they used their disposal time. She said:

I have my students write a journal on Mondays and I ask them to write about what they did on the weekend. I consistently get student answers like, "I played my video games," "I did not go outside," I did not exercise at all." It's like they are talking a different language - it's like their life.

As stated previously, Heather found students at her school to be uninterested in PA as well. However, she extended her perceptions about student values:

I see a change in what is valued in sport and work-the commitment is just not there from today's students. What worries me is that these same students are then becoming teachers and it (PA) is not part of their lifestyle so the cycle continues.

\section{Discussion}

This study aimed to explore the influences on elementary school students, teachers' and administrators' participation in school-based PA opportunities and overall student DPA levels. More concisely, what factors were believed to influence consistent, school-wide engagement in DPA (20 minutes per day), leisure time intramurals and competitive sport teams, and organized physical activities (i.e. fitness clubs or low-organizational games) during nutrition breaks.

A physically active, school culture is defined in the literature as a school that encourages students to be more active (Fein, Plotnikoff, Wild, \& Spence, 2004; Fuller, Sabiston, Karp, Barnett, \& O'Loughlin, 2011; Mahar et al., 2006), one that maximizes opportunities for student PA, and/or a culture that explicitly values PA(Barnett et al., 2009a; Fuller et al., 2011). Thus, it is clear that school leaders (i.e. teachers, administrators, student leaders) are the driving forces behind school-based PA opportunities. However, participants in this study discussed an abundance of factors that restricted 
their ability to effectively promote the importance of PA to students and staff. Overwhelmingly, participants claimed their desire to learn about strategies that traverse these barriers, and help them comfortably insert DPA into their already demanding timetable, while satisfying expectations across the curriculum. In the following paragraphs, practical and practiced solutions will be discussed relative to the school-based, cultural factors outlined by study participants that influenced the inclusion of DPA into their elementary school's daily timetable.

\subsection{School Values}

Frustration with 21st century parent and student values relative to the importance of DPA was apparent in many of the participants' comments. A culture of blame for diminishing school-based PA and students PA levels was attributed by teachers/administrators to the perceived negative values the students and/or their parents/guardians' held towards PA. Participants believed they had been trying to promote DPA to their students in a variety of forums, but student reactions were unrewarding, and other teachers in the school were not dedicating the required time to DPA. Essentially, the effort to create and lead physically active events was not worth the time teachers invested.

Earlier studies have confirmed that student PA levels are associated with teacher and principal values, attitudes, and behaviors surrounding PA(Barnett et al., 2006; Bauer et al., 2006; Dyment \& Bell, 2007; Groft, Hagen, Miller, Cooper, \& Brown, 2005; MacQuarrie et al., 2008). Other researchers suggest that when teachers facilitate PA opportunities during leisure times at elementary schools, student DPA levels are positively and significantly influenced (Loucaides et al., 2009; Mahar et al., 2006; Stewart, Dennison, Kohl, \& Doyle, 2004; Verstraete, Cardon, De Clercq, \& DeBourdeaudhuij, 2006). Generally, elementary-aged students who perceived their school valued PA were more active at school (Fein et al., 2004; Zhang, Middlestadt, \& Ji, 2007).

Barnett et al. (2009a) discovered that in physically active school cultures, promoting PA through school policies was not sufficient; school leaders (i.e. administrators and teachers) believed it was more important to educate the school community (i.e. students, parents) about the value of PA. Schools may not be able to change students' and parents'/guardians' PA values; therefore, it is important that elementary schools promote active lifestyles by providing and engaging in DPA. In order to increase parent/guardian awareness of active lifestyles, encourage them to volunteer ina school-based PA event (i.e. Terry Fox walk/runs, walk to school events, play days). Promote parents/guardians and students as partners in PA and school staff will often follow. Other school culture studies have shown that a school's cultural system changes individuals more often than the individuals change the system (Fullan, 1993, 2001, 2005a).

Elementary schools may also consider making DPA a school-wide event so it is not left to individual teachers to prepare and deliver. At a designated time in the day, verbal DPA instructions over the school's intercom can lead classes through 20 minutes of activity, or gathering classes in the school's gymnasium (or outside space) for a student-led dance/zumba session are both successful strategies (Rickwood \& Foisy, 2014). Furthermore, some schools have created a DPA committee (staff and student members) that design and lead weekly DPA activities for the entire school. Many of the school leaders in this study aligned the lack of consistent application of DPA to the dynamics of administration. Every two to three years, a new principal would be assigned to the school coveting their own set of PA values. The established DPA committee could serve as front line supporters that justify the rewards of school-wide DPA to new administrators.

Identifying parents/guardiansor other PA experts (i.e. personal trainers, Yoga instructors, marathon runners, local Olympic athletes, post-secondary students in PE programs) and having these individuals lead school-wide DPA days is another strategy that motivates students to be active, and relieves the pressures of preparing DPA lesson(s) for individual teachers. As expressed in the data, new teachers had greater difficulty inserting DPA into their timetables due to part-time workloads between two schools, or simply the dynamics of "learning the ropes" as a new teacher. If DPA is a part of the daily timetable, "fitting DPA in" is no longer an issue for new and/or experienced teachers. Moreover, the mutual participation of parent (or adult role model) and child in school-based PA has shown to positively influence elementary students’ DPA levels (Jurg, Kremers, Candel, Van der Wal, \& Meij, 2006).

In line with the importance of supportive school values regarding PA are the purposes PA and PE serve in schools. Several of the participants either used, or observed colleagues using PA, or the removal of PE classes, as punishment for inappropriate student behaviours. Teacher strategies such as forcing students to run laps around school grounds, or taking away nutrition breaks were heavily relied upon approaches to managing student behaviours. When school leaders use PA in these ways, students begin believing that PA and PE classes are negative experiences, and their willingness to participate in purposeful movement activities may decrease. In turn, teacher-student relationships are impaired when PA is used for punishment, particularly for those students who are not physically active on a daily or weekly basis. Positive relationships among student and teachers are important and have been associated with an elementary student's decision to participate in school-based PA opportunities (Boyle, Jones, \& Walters, 2008; Lounsbery, Bungum, \& Smith, 2007).It is well-documented that elementary students who are physically active at school are more eager to learn (Strong et al., 2005), have better information retention (Field, Diego, \& Sanders, 2001), longer attention spans (Sibley 
\& Etnier, 2003), and exhibit positive classroom behaviours (Mahar et al., 2006). Thus, removing PE class or denying students their nutrition breaks only generates more of the undesirable classroom behaviours that teachers are trying to eliminate.

\subsection{Managing the Uncontrollables}

Teachers and administrators talked about the changing culture of Northern Ontario elementary schools, and how it was influencing DPA levels of students and in general, the quality and quantity of school-based PA opportunities. Declining student enrolment was believed by most participants to be a significant barrier in promoting and sustaining active school cultures. For example, Katie exclaimed:

The more kids you have in the school, the more you can offer. The less you have, the harder it is to run multiple teams because there are just not enough students to go around.

This variable was also noted as a deterrent for Ontario's secondary teachers when promoting PA opportunities in their schools (Rickwood \& Foisy, 2014; Rickwood \& Singleton, 2012).

As student enrolment continues to wane, fewer full-time teachers are being hired. Many new teachers are leaving education due to the lack of job prospects, and are taking key PE and PA leadership skills with them. With less teachers in a school building, this means that replacing experienced PA leaders (i.e. teacher-coaches, intramural leads, sport specialists) can be challenging. As indicated earlier, Ray stated that he was not able to hire teachers with sport backgrounds or special interests in PE and PA unless these teachers were high on the seniority list. Thus, if Ray knew he was losing a long-time teacher-coach or school sport leader to retirement, it was unlikely that he could replace that individual with a teacher who was qualified and capable of taking over these extra-curricular duties. Furthermore, new teachers are often assigned to long-term, half time positions between two schools. With this comes the questions of how much time and effort will the part-time teacher dedicate to each school, and is their teaching resume more important than their coaching resume in securing full-time employment.

An additional barrier to sustaining an active school culture is the adjustment of the elementary timetable from one lunch period to two, shorter nutrition breaks. Ontario's Ministry of Education based this change on research that determined students learned better with short breaks, but did not consider the influence it would have on intramurals, other leisure time PA programs, and DPA levels of students. Teachers in this study highlighted the difficulties of completing classroom work, dealing with student issues and other job-related responsibilities, and then trying to plan and lead PA options during a 20-minute nutrition break. Previous studies support these teachers' concerns around the revised timetable; school policies that demote leisure time minutes (i.e. nutrition breaks) and restrict and/or remove leisure times during the school day produce fewer student options for PA(Bocarro, Kanters, Casper, \& Forrester, 2008; Rentner, Scott, \& Kober, 2006) and decrease students’ DPA levels (Koplan et al., 2005; Trudeau \& Shephard, 2005).

The aforementioned barriers to school-based PA and motivating students to attain the recommended DPA standards are realities that plague a majority of schools across Ontario. Some elementary schools find ways to overcome these obstacles by using the assets they have to promote PA across the curriculum. In one studied school, Jessica told the research team that a grade six teacher in her school taught his students how to organize and deliver low-organizational games, and then had them demonstrate these skills to lead games at nutrition breaks for interested students. In this particular school, this group of students was referred to as the "Recess Revival Team." It was supervised by the teacher on duty but was completely managed by the junior students. Jessica had watched this program flourish over her past two years at the school and with confidence, said she observed 30-40 students from multiple grades participating daily in these leisure time PA opportunities. Additionally, she noticed that other junior teachers in her school started their own revival teams with their classes, and it had become something primary students were looking forward to being a part of when they entered the junior grades. This finding reaffirms other studies' results in that active role models who outwardly demonstrate healthy behaviours can influence how PA is perceived by school staff and students (Stratton \& Mullan, 2005; Varpalotai \& Thomas, 2007, 2009).

This concept can be applied to a school-based, teacher-coach mentorship program. Although new, full-time teachers are in decline, each school can develop a mentorship committee that connects a new teacher with an experienced teacher-coach or PA leader. Regardless of how long the new teachers are at the school, their mentors can pass on crucial PA leadership skills that can then be applied and practiced at any school. There is the possibility that the school mentoring the new teacher-coaches may not benefit from their labours, but some school(s) will. Mentorship could include providing the new teacher with a sport binder that contains all the details required to effectively lead a sport team, intramural program or fitness club (i.e. practice drills, skills required to play, teaching techniques, professional development workshops, game tactics, team numbers, tournament formats, budgets). In turn, the mentee would be required to shadow their mentor during team practices, games and other team events and assist when necessary. If the mentee remained with the school into a second year, they assumed the head role of coach or leader, and the mentor 
moves into a consultant's role.

As in this study, elementary teachers in other similar studies believe there is not enough time in the day/week to fit in DPA, intramurals, leisure time PA events and inter-murals, and manage curricular obligations (Rickwood \& Foisy, 2014; Rickwood \& Singleton, 2012; Rickwood, Temple \& Meldrum, 2011b). A solution may be dedicating a specific time every week for student and staff participation in school-based PA. Thelong-standing, Ontario private school model of mandated PA implanted into the weekly timetablehas been a successful strategy for sustaining and promoting DPA.

Findings from this study suggest that there are several intangibles inside and outside school walls that influence (positively and negatively) school-based PA and DPA levels of elementary students. Therefore, schools must rely upon their internal resources to protect and maintain their pre-established or evolving culture of PA. Teachers, students, parents, and administrators control their own actions and values - it is up to this collective to promote PA to their colleagues and peers regardless of outside forces.

\subsection{Study Limitations}

Administration in both schools cited teacher job action in refute of Bill 115 as a key inhibitor to a more welcoming response to the call for participants. At the time of this study, teachers across the district had just ceased a full withdrawal of extracurricular services. Furthermore, because of the limited sample of teachers and administrators studied from four schools in northern Ontario, study findings are not generalizable.

\section{References}

Active Healthy Kids Canada. (2013). Are we driving our kids to unhealthy habits? from http://www.activehealthykids.ca

Adami, H. O., Day, N. E., Trichopoulos, N. E., \& Willett, W. C. (2001). Primary and secondary prevention in the reduction of cancer morbidity and mortality. European Journal of Cancer, 37, S118-S127. http://dx.doi.org/10.1016/S0959-8049(01)00262-3

Anderson, G. (1993). Fundamentals of Educational Research. London: Falmer Press.

Barnett, T. A., O'Loughlin, J. L., Gauvin, L., Paradis, G., \& Hanley, J. (2006). Opportunities for student physical activity in elementary schools: A cross-sectional survey of frequency and correlates. Health Education and Behavior, 33, 215-232. http://dx.doi.org/10.1177/1090198105277855

Barnett, T. A., O'Loughlin, J. L., Gauvin, L., Paradis, G., Hanley, J., McGrath, J., \& Lambert, M. (2009a). School opportunities and physical activity frequency in nine year old children. International Journal of Public Health, 54, 1-8. http://dx.doi.org/10.1007/s00038-009-7110-0

Barnett, T. A., O'Loughlin, J. L., Gauvin, L., Paradis, G., Hanley, J., McGrath, J., \& Lambert, M. (2009b). School opportunities and physical activity frequency in nine year old children. International Journal for Public Health, 54, 1-8. http://dx.doi.org/10.1007/s00038-009-7110-0

Bauer, K. W., Patel, A., Prokop, L. A., \& Austin, B. (2006). Swimming upstream: Faculty and staff members from urban middle schools in low income communities describe their experience implementing nutrition and physical activity initiatives. Preventing Chronic Disorders, 3, 1-9.

Belanger, M., Gray, D. K., O'Loughlin, J. L., Paradis, G., Hutcheon, J., Maximova, K., \& Hanley, J. (2009). Participation in organized sports does not slow declines in physical activity during adolescence. International Journal of Behavioral Nutrition and Physical Activity, 6.

Bocarro, J., Kanters, M. A., Casper, J., \& Forrester, S. (2008). School physical education, extracurricular sports, and lifelong active living. Journal of Teaching in Physical Education, 27, 155-166.

Boyle, S., Jones, G., \& Walters, S. (2008). Physical activity among adolescents and barriers to delivering physical education in Cornwall and Lancashire, UK: a qualitative study of heads of PE and heads of schools. BMC Public Health, 8, 273-280. http://dx.doi.org/10.1007/s00038-009-7110-0

Cohen, D. A., Scott, M., Zhen, W. F., McKenzie, T. L., \& Porter, D. (2008). School design and physical activity among middle school girls. Journal of Physical Activity and Health, 5, 719-731.

Colley, R. C. (2011). Physical activity of Canadian children and youth: accelerometer results from 2007-2009 Canadian Health Measures Survey. Health Reports, 22, 15-23.

Comte, M. (2013). Patterns of weekday and weekend physical activity in youth in 2 Canadian provinces. Applied Physiology, Nutrition and Metabolism, 38, 115-119. http://dx.doi.org/10.1139/apnm-2012-0100

Datar, A., \& Sturm, R. (2004). Physical education in elementary school and body mass index: Evidence from the early 
childhood longitudinal study. American Journal of Public Health, 94, 1501-1506. http://dx.doi.org/10.1139/apnm-2012-0100

Dyment, J. E., \& Bell, A. C. (2007). Grounds for movement: green school grounds as sites for promoting physical activity. Health Education Research, 23, 952-962. http://dx.doi.org/10.1139/apnm-2012-0100

Fein, A. J., Plotnikoff, R. C., Wild, C., \& Spence, J. C. (2004). Perceived environment and physical activity in youth. International Journal of Behavioral Medicine, 11, 135-142. http://dx.doi.org/10.1207/s15327558ijbm1103_2

Field, T., Diego, M., \& Sanders, C. (2001). Exercise is positively related to adolescent's relationships and academics. Adolescence, 36, 105-110.

Fullan, M. (1993). Change forces: Probing the depths of educational reform. London, New York, Philadephia: The Falmer Press.

Fullan, M. (2001). Leading in a Culture of Change. San Francisco, CA: Jossey-Bass.

Fullan, M. (2005a). Leadership and sustainability. Thousand Oaks, CA: Corwin Press; Toronto: Ontario Principal's Council.

Fuller, D., Sabiston, C., Karp, I., Barnett, T., \& O'Loughlin, J. (2011). School sports opportunities influence physical activity in secondary school and beyond. Journal of School Health, 81, 449-454. http://dx.doi.org/10.1111/j.1746-1561.2011.00613.x

Groft, J. N., Hagen, B., Miller, N. K., Cooper, N., \& Brown, S. (2005). Adolescent health: a rural community's approach. Rural and Remote Health, 5, 366-378.

Hammersley, M., \& Atkinson, P. (1983). Ethnography: Principles in practice (3rd ed.). New York: Routledge.

Haug, E., Torsheim, T., \& Samdal, O. (2008). Physical environmental characteristics and individual interests as correlates of physical activity in Norwegian secondary schools: The health behavior in school-aged children study. International Journal of Behavioral Nutrition and Physical Activity, 5, 47-56. http://dx.doi.org/10.1186/1479-5868-5-47

Homans, G. (1950). The Human Group. New York: Harcourt Brace Jovanovich.

Horton, E. S. (2009). Effects of lifestyle changes to reduce risks of diabetes and associated cardiovascular risks: results from a large scale efficacy trials. Obesity, 17, S43-S48. http://dx.doi.org/10.1186/1479-5868-5-47

Janssen, I., \& LeBlanc, A. G. (2010). Systematic review of the health benefits of physical activity and fitness in school-aged children and youth. International Journal of Behavioral Nutrition and Physical Activity, 7, 40-56. http://dx.doi.org/10.1186/1479-5868-7-40

Janssen, M. A. (2008). Dose-response relation between physical activity and blood pressure in youth. Medicine and Science in Sports and Exercise, 40, 1007-1012. http://dx.doi.org/10.1249/MSS.0b013e318169032d

Jurg, M. E., Kremers, S. P., Candel, M., Van der Wal, M. F., \& Meij, J. (2006). A controlled trial of a school-based environmental intervention to improve physical activity in Dutch children: JUMP-in, kids in motion. Health Promotion International, 21, 320-330. http://dx.doi.org/10.1093/heapro/dal032

Kantomaa, M., Tammelin, T., Ebeling, H., \& Tannila, A. (2008). Emotional and behavioral problems in relation to physical activity in youth. Medicine and Science in Sports and Exercise, 40, 1749-1756. http://dx.doi.org/10.1249/MSS.0b013e31817b8e82

Koplan, J. P., Liverman, C. T., \& Kraak, V. I. (2005). Preventing childhood obesity: Health in the balance. Washington, D.C.: National Academies Press.

Lanningham, F. L., Foster, R. C., McCrady, S. K., Manohar, C., Jensen, T., Mitre, N., Levine, J. (2008). Changing the school environment to increase physical activity in children. Obesity, 16, 1849-1853. http://dx.doi.org/10.1249/MSS.0b013e31817b8e82

Leatherdale, S. T., Manske, S. R., Faulkner, G., Arbour, K., \& Bredin, C. (2010). A multi-level examination of school programs, policies and resources associated with physical activity among elementary school youth in the PLAY-ON study. International Journal of Behavior, Nutrition and Physical Activity, 7, 6-19. http://dx.doi.org/10.1249/MSS.0b013e31817b8e82

Leatherdale, S. T., \& Rynard, V. (2013). A cross-sectional examination of modifiable risk factors for chronic disease among a nationally representatitve sample of youth: are Canadian students graduating high school with a failing grade for health? BMC Public Health, 13. 
Loucaides, C., Jago, R., \& Charalambous, I. (2009). Promoting physical activity during school break times: piloting a simple, low cost intervention. Preventive Medicine, 48, 332-334. http://dx.doi.org/10.1016/j.ypmed.2009.02.005

Lounsbery, M., Bungum, T., \& Smith, N. (2007). Physical activity opportunity in K-12 public school settings: Nevada. Journal of Physical Activity and Health, 4, 30-38.

MacQuarrie, C., Murnaghan, D., \& MacLellan, D. (2008). Physical activity in intermediate schools: The interplay of school culture, adolescent challenges, and athletic elititism. The Qualitative Report, 13, 262-277.

Mahar, M., Murphy, S., Rowe, D., Golden, J., Shields, A., \& Raedeke, T. (2006). Effects of a classroom-based program on physical activity and on-task behavior. Medicine and Science in Sports and Exercise, 38, 2086-2094. http://dx.doi.org/10.1249/01.mss.0000235359.16685.a3

Malina, R. M. (2001). Physical activity and fitness: Pathways from childhood to adulthood. American Journal of Human Biology, 13(2), 162-172. http://dx.doi.org/10.1002/1520-6300(200102/03)13:2<162::AID-AJHB1025>3.0.CO;2-T

Merton, R. K. (1968). Social Theory and Social Structure. Glencoe, IL: The Free Press.

Miles, M., \& Huberman, M. (1984). Qualitative data analysis: A source book for new methods. Thousand Oaks, CA: Sage Publications.

Ministry of Education Curriculum. (2005) Retrieved August 29, 2014, from http://www.edu.gov.on.ca/eng/teachers/dpa.html

Naylor, P. J., Macdonald, H. M., Zebedee, J. A., Reed, K. E., \& McKay, H. A. (2006). Lessons learned from Action Schools! BC - An 'active school' model to promote physical activity in elementary schools. Journal of Science and Medicine in Sport, 9, 413-423. http://dx.doi.org/10.1016/j.jsams.2006.06.013

Noor, K. B. (2008). Case study: a strategic research methodology. American Journal of Applied Sciences, 5, 1602-1604. http://dx.doi.org/10.3844/ajassp.2008.1602.1604

Parsons, T. (1951). The Social System. New York: Free Press.

Patton, M. (1987). How to Use Qualitative Methods in Evaluation. California: Sage Publications.

Rentner, D. S., Scott, C., \& Kober, N. (2006). From the capital to the classroom: Year 4 of no child left behind. Washington, D.C.: Center for Education Policy.

Rickwood, G., \& Foisy, C. (2014). Active role models at the core of active secondary school cultures. Physical and Health Education Academic Journal, 6 (1).

Rickwood, G., \& Singleton, E. (2012). A cultural approach to promoting physical activity in secondary schools. Physical and Health Education Academic Journal, 4 (3).

Rickwood, G., Temple, V., \& Meldrum, J. (2011a). The reliability and validity of a school-based physical activity survey. Physical and Health Education Academic Journal, 3 (1).

Rickwood, G., Temple, V., \& Meldrum, J. (2011b). School-based physical activity opportunities: perceptions of elementary parents, teachers, and administrators. Physical and Health Education Academic Journal, 3 (2).

Rosenfeld, A. (2004). Harvard, soccer and over-scheduled families. Youth Studies Australia, 23, 15-18.

Ruiz, J., \& Ortega, F. (2009). Physical activity and cardiovascular disease risk factors in children and adolescents. Current Cardiovascular Risk Reports, 3(4), 281-287. http://dx.doi.org/10.3844/ajassp.2008.1602.1604

Schein, E. (1999). The Corporate Culture Survival Guide: Sense and Nonsense about Culture Change. San Francisco: Jossey-Bass Publishers.

Schein, E. H. (1985). Organizational culture and leadership. San Francisco: Jossey-Bass.

Schein, E. H. (1990). Organizational culture. American Psychologist, 45, 109-119. http://dx.doi.org/10.1037/0003-066X.45.2.109

Sibley, B., \& Etnier, J. (2003). The relationship between physical activity and cognition in children: a meta-analysis. Paediatric Exercise Science, 15, 243-256.

Stewart, J., Dennison, D., Kohl, H., \& Doyle, A. (2004). Exercise level and energy expenditure in the TAKE 10! In-class physical activity program. Journal of School Health, 74, 397-400. http://dx.doi.org/10.1037/0003-066X.45.2.109

Stratton, G., \& Mullan, E. (2005). The effect of multi-colour playground markings on children's physical activity level 
during recess. Preventive Medicine, 41, 8258-8833. http://dx.doi.org/10.1016/j.ypmed.2005.07.009

Strong, W. B., Malina, R. M., Blimke, C. J. R., Daniels, S. R., Dishman, R. K., \& Gutin, B. (2005). Evidence based physical activity for school-age youth. The Journal of Paediatrics, 146, 732-737. http://dx.doi.org/10.1016/j.ypmed.2005.07.009

Telama, R., Yang, X., Viikari, J., Valimaki, I., Wanne, O., \& Raitakari, O. (2005). Physical activity from childhood to adulthood: a 21-year tracking study. American Journal of Preventive Medicine, 28, 267-273. http://dx.doi.org/10.1016/j.amepre.2004.12.003

Tremblay, M., Shields, M., Laviolette, M., Craig, C. L., Janssen, I., \& Connor, G. (2010). Fitness of Canadian children and youth: results from the 2007-2009 Canadian Health Measures Survey. Health Reports, 21, 1-7.

Trudeau, F., \& Shephard, R. J. (2005). Contribution of school programs to physical activity levels and attitudes in children and adults. Sports Medicine 25, 89-105. http://dx.doi.org/10.2165/00007256-200535020-00001

Varpalotai, A., \& Thomas, M. (2007). The perceptions of stakeholders in Canada and Wales on health education in rural communities: A comparative study. Education in Rural Australia, 17, 59-69.

Varpalotai, A., \& Thomas, M. (2009). Final Report: West Elgin Secondary School Wellness Centre Survey (2007-2008). In F. o. Education (Ed.). London, ON: University of Western Ontario.

Verstraete, S., Cardon, G. M., De Clercq, D., \& DeBourdeaudhuij, I. (2006). Increasing children's physical activity levels during recess periods in elementary schools: the effects of providing game equipment. European Journal of Public Health, 16, 415-419. http://dx.doi.org/10.1093/eurpub/ck1008

Warren, C. B., \& Karner, T. X. (2010). Discovering Qualitative Methods: Field research, Interviews, and Analysis (Second ed.). New York: Oxford University Press.

Williden, M., Taylor, R., McAuley, K., Simpson, J., Oakley, M., \& Mann, J. (2006). The APPLE project: An investigation of the barriers and promoters of healthy eating and physical activity in New Zealand children aged 5-12 years. Health Education Journal, 65, 135-148. http://dx.doi.org/10.1177/001789690606500204

Yin, R. (1994). Case Study Research: Design and Methods (2nd ed.). Beverly Hills, CA: Sage Publications.

Zhang, J., Middlestadt, S. E., \& Ji, C. (2007). Psychosocial factors underlying physical activity. International Journal of Behavioral Nutrition and Physical Activity, 4, 1479-1488. http://dx.doi.org/10.1186/1479-5868-4-38

\section{(cc) $\mathrm{BY}$}

This work is licensed under a Creative Commons Attribution 3.0 License. 